\title{
Hydrogel-Mediated Direct Patterning of Conducting Polymer Films with Multiple Surface Chemistries
}

\author{
SooHyun Park, \\ Department of Biomedical Engineering, The Pennsylvania State University, 205 Hallowell \\ Building, University Park, PA 16802, USA

\section{Guang Yang,} \\ Department of Biomedical Engineering, The Pennsylvania State University, 205 Hallowell \\ Building, University Park, PA 16802, USA

\section{Nrutya Madduri,} \\ Department of Biomedical Engineering, The Pennsylvania State University, 205 Hallowell \\ Building, University Park, PA 16802, USA
}

\begin{abstract}
Mohammad Reza Abidian Prof., and Department of Biomedical Engineering, Department of Chemical Engineering, Department of Materials Science and Engineering, The Pennsylvania State University, W342 Millennium Science Complex, University Park, PA 16802, USA

\section{Sheereen Majd Prof.}

Department of Biomedical Engineering, Department of Engineering Science and Mechanics, Materials Research Institute, The Pennsylvania State University, 218 Hallowell Building, University Park, PA 16802, USA
\end{abstract}

\begin{abstract}
This manuscript describes a simple and versatile approach for patterning spatially addressable films of conducting polymers with various surface chemistries using agarose stamps. Conducting polymers (CPs) have been applied in a number of fields ranging from flexible electronics ${ }^{[1]}$ and sensing ${ }^{[2,3]}$ to energy storage. ${ }^{[4,5]}$ The growing interest in these materials stems from their unique and tunable physical and chemical properties. ${ }^{[6]} \mathrm{CPs}$ have conjugated double-bonded backbone that provides electronic conductivity after doping. ${ }^{[7]}$ Electrochemical oxidation and reduction of these polymers can change their color, ${ }^{[8]}$ volume, ${ }^{[9]}$ conductivity, ${ }^{[6]}$ and wettability. ${ }^{[10]}$ Moreover, CPs can easily be decorated with functional molecules including bioactive proteins and drugs or can entrap these molecules for controlled release upon electrical stimulation. ${ }^{[11-14]}$ In the biomedical field, surfaces with patterned films of $\mathrm{CP}$ offer attractive platforms for studies of in vitro cell attachment and growth, ${ }^{[15-18]}$ tissue regeneration, ${ }^{[19-21]}$ neural electrodes, ${ }^{[22,23]}$ or biosensing. ${ }^{[24-26]}$ In this context, polypyrrole (PPy) ${ }^{[27,28]}$ and poly(3,4-ethylenedioxythiophene) (PEDOT) ${ }^{[18,29]}$ have become particularly popular due to their superior conductivity, chemical stability, and biocompatibility.
\end{abstract}

Correspondence to: Sheereen Majd, Prof..

Supporting Information

Supporting Information is available from the Wiley Online Library or from the author. 
These polymers are commonly synthesized through chemical or electrochemical polymerization. ${ }^{[6]}$ In addition, CPs can be patterned either through selective removal of parts of an existing film ${ }^{[29-31]}$ or selective deposition of the polymer. ${ }^{[17,32-41]}$ To date, both approaches have been employed through variety of techniques such as inkjet printing, ${ }^{[17]}$ infrared laser, ${ }^{[40]}$ photolithography, ${ }^{[32,39]}$ e-beam lithography, ${ }^{[34,35]}$ dip-pen nanolithography, ${ }^{[37,38]}$ and microcontact printing. ${ }^{[31,36,41,42]}$ Among these techniques, microcontact printing offers a low-cost and versatile approach to pattern CP films, with resolutions acceptable for most biomedical applications, ${ }^{[42,43]}$ compared to other methods where sophisticated instruments are often required. Microcontact printing is accessible to any ordinary laboratory since stamps are prepared from elastomeric materials, such as poly dimethylsiloxane (PDMS), casted from a microfabricated mold. ${ }^{[4]}$ Within the past few years, hydrogels have been explored as an alternative for the traditional PDMS stamps in microcontact printing of hydrophilic substances. ${ }^{[45-50]}$ Porous and hydrated nature of hydrogels enables these stamps to absorb aqueous solutions of cells ${ }^{[49,50]}$ and biomolecules ${ }^{[45-48]}$ for subsequent patterning. These stamps have also been utilized in fabrication of micro- and nano-scale structures on glass substrates. ${ }^{[51]}$ Recently, Larsen and colleagues employed hydrogel stamps to deliver an etchant chemical for selective removal of parts of a preformed CP film, producing a patterned polymer film. ${ }^{[31]}$ In another intriguing study, these authors further extended the application of hydrogel stamps to generate patterned $\mathrm{CP}$ films with various chemistries in register. ${ }^{[52]}$ This subtractive approach, however, required several consecutive steps for generating the patterned CP film with multiple chemistries.

Here, we present a different and novel approach to apply hydrogel stamps for patterning CP films with multiple chemistries in a single-step process. In this approach, referred to as hydrogel-mediated electropolymerization, wet hydrogel stamps deliver polymer precursor solutions (i.e. monomer and dopants) to the electrode surface and upon application of a current, CP film with controlled thickness forms only in the areas of contact between the hydrogel and electrode (Figure 1A). This solution-free technique affords simultaneous deposition of different $\mathrm{CP} /$ dopant compositions on a substrate in parallel within a single deposition step. In addition, the biocompatible and wet hydrogel stamps provide an ideal environment for storage and delivery of bioactive molecules to the site of polymerization, enabling easy entrapment of these biomolecules in the produced film of CP.

In order to generate patterned films of PPy, we placed an agarose stamp, inked with the monomer/dopant (pyrrole (Py)/polystyrene sulfonate (PSS)) solution, into contact with a conductive substrate (in this case, gold-coated plastic cover slip). We then applied a current between the gold substrate and the stamp, using a three-electrode setup, which resulted in the electropolymerization of Py at the sites of contact between the stamp and gold substrate (Figure 1A). In this method, the hydrogel acts as a carrier of the polymer precursors and thus, restricts the polymer electrodeposition to selected areas of the gold substrate. Figure 1B illustrates a representative substrate patterned with PPy films using this technique. To assess the flexibility of this method to generate different patterns of $\mathrm{CP}$, we employed agarose stamps with circular posts of diameters ranging from $40 \mu \mathrm{m}$ to $1 \mathrm{~mm}$ and stamps with linear posts of $100 \mu \mathrm{m}$ width to pattern PPy films. Application of these stamps for electropolymerization produced positively-patterned PPy films with high-fidelity, as illustrated in Figure 2 A-D. The graph in Figure 2 E shows an excellent linear correlation (R 
${ }^{2}=0.9797$ ) between the agarose stamp post size and the diameter of the deposited PPy spots. These results demonstrate the versatility of the present technique to generate patterns of CP films with various sizes and shapes.

To better characterize the resultant CP films, we examined their thickness and electrical property. For thickness measurements, we applied agarose stamps loaded with $0.1 \mathrm{M} \mathrm{Py/0.1}$ M PSS for electrodeposition with time durations of 3-15 min and characterized the deposited PPy films on gold substrates using field emission scanning electron microscopy (FESEM). FESEM images (Figure S1 in the Supporting Information) revealed that the polymer thickness increased linearly with an increase in electrodeposition time, as depicted in Figure $2 \mathrm{H}$. This data shows that electropolymerization through hydrogel stamp allows controlling of the deposited CP film thickness, similar to the solution-based electrodeposition. For electrical property measurements, we evaluated the impedance of the gold electrodes at $1 \mathrm{kHz}$ before and after deposition of patterned PPy film. As Figure $2 \mathrm{G}$ shows, the patterned PPy film reduced the impedance of the gold substrates by approximately $99.4 \%$, confirming the conductivity of the produced PPy films on gold. These results are in good agreement with the previous reports on surface modification of neural electrodes with CPs (including PPy) to lower the impedance of these electrodes for improved neural recordings. ${ }^{[22,27,53]}$

The absorbent nature of hydrogels makes them capable of storing materials and solutions for multiple deliveries. Indeed, agarose stamps loaded with biomolecules have been previously applied for patterning 30-100 arrays of biomolecules without intermediate inking. [45-48] Based on this interesting capability, we hypothesized that a hydrogel stamp loaded with monomer and dopant would be able to deliver these materials to several substrates, one after another, for selective deposition of polymer films on these electrodes. To test this hypothesis, we inked an agarose stamp with $0.3 \mathrm{M}$ Py/0.3 M PSS and applied it for consecutive electrodeposition of PPy on 10 gold substrates. This stamp successfully deposited PPy on all the gold substrates without any detectable difference in the quality of polymer film, specifically the color, intensity, and the amount of defects within these films (Figure S2 in Supplementary Information). The hydrogel-mediated electropolymerization technique presented here can, hence, be applied for large-scale production of patterned CP films in a rapid and efficient manner.

Patterned CPs are particularly attractive when they present multiple chemistries in a spatially addressable fashion. ${ }^{[52]}$ These films, for instance, provide an appealing platform for studying interactions of cells with surfaces of various chemistries, which can simply be achieved through incorporation of different dopants or bioactive molecules in the CP film. To examine the capability of the present technique to generate patterned CPs with multiple chemistries, we first tested if we can control the CP polymerization on a substrate spot by spot by selective inking of the posts on a stamp. To this end, we used a $2 \%(\mathrm{w} / \mathrm{v})$ agarose stamp that was previously loaded with $0.5 \mathrm{M}$ of Py (by immersing the entire stamp in the monomer solution) and individually inked alternating posts on the stamp with a $0.5 \mathrm{M}$ PSS dopant solution, leaving other posts with no dopant. Applying this stamp for the electropolymerization led to the deposition of PPy only on the spots where the corresponding posts were inked with the dopant solution, while no polymer growth was 
observed in the rest of the substrate despite the presence of Py throughout the stamp (Figure $3 \mathrm{~A}$ ). It should be noted that the polymerization is believed to proceed via a radical-radical coupling mechanism in which the counterions (dopant) play an important role in balancing the natural repulsion between the radicals and the formation of the polymer on the electrode surface. ${ }^{[54]}$ Figure 3 B illustrates the PSU logo created by the selective inking of the hydrogel posts. These results confirm that we can address different spots in a patterned $\mathrm{CP}$ film, produced by this method, individually. Employing the same concept, we fabricated a patterned PPy film with multiple chemistries by selective inking of posts of a $0.5 \mathrm{M}$ Pyloaded stamp with one of three different dopant solutions: 0.5 M PSS, $0.25 \mathrm{M}$ dodecylbenzenesulfonate (DBS), and $0.5 \mathrm{M}$ perchlorate $\left(\mathrm{ClO}_{4}\right)$. The presence of these dopants in different spots was confirmed either by attenuated total reflectance-Fourier transform infrared spectroscopy (ATR-FTIR) or by energy dispersive spectroscopy (EDS). Using ATR-FTIR, we were able to detect the presence of DBS and PSS in the PPy film, while $\mathrm{ClO}_{4}$ was not easily detectable (Figure $3 \mathrm{D}$ ). We therefore, applied EDS as a complimentary detection method by which we were able to confirm the presence of PSS and $\mathrm{ClO}_{4}$ in PPy patterned spots (Figure $3 \mathrm{E}$ ). In Figure $3 \mathrm{D}$, the vibration bands at $3433 \mathrm{~cm}^{-1}$ correspond to the N-H stretching of PPy and the absorption at $1540 \mathrm{~cm}^{-1}$ represents the C$\mathrm{C}$ and $\mathrm{C}=\mathrm{C}$ stretching in the PPy ring and can hence, be regarded as characteristic absorption of PPy. The absorption range of $2800-2990 \mathrm{~cm}^{-1}$ corresponds to the long alkyl chain of DBS. ${ }^{[55]}$ From the EDS data in Figure $3 \mathrm{E}, \mathrm{Cl}$ from $\mathrm{ClO}_{4}$ and $\mathrm{S}$ from PSS were clearly detected. These findings demonstrate that a single hydrogel stamp can be applied to deliver multiple distinct dopants and to produce patterned $\mathrm{CP}$ films with various chemistries and properties on the same substrate in a single-step procedure.

Decoration of CPs with bioactive molecules such as proteins is essential for most biomedical applications of these polymers. ${ }^{[11,14,26,56]}$ It has been previously demonstrated that such molecules can easily be entrapped within the CP network during electropolymerization process. ${ }^{[11,26]}$ To assess the applicability of the hydrogel-mediated electrodeposition for the fabrication of CP films with entrapped biomolecules, we included D-biotin molecules in the inking solution used for the hydrogel stamp and tested the resultant PPy films for the presence of biotin following a procedure previously reported by George et al. ${ }^{[56]}$ In this case, DBS was used as a dopant (at very low concentration in order to favor the inclusion of D-biotin). Briefly, a solution of 0.1 M Py, 0.01 M DBS, and 0.04 M D-biotin was prepared and used to ink an agarose stamp that was subsequently applied for electrodeposition of a patterned PPy film. We confirmed the presence of D-biotin in the resulting PPy films by fluorescence imaging and ATR-FTIR. When exposed to the fluorescent-labeled streptavidin (a protein that binds to biotin with high affinity), biotin-containing PPy films showed significantly higher fluorescence intensity compared to the control PPy films with no biotin (Figure 3 F, G). Moreover, ATR-FTIR spectroscopy of the biotin-containing PPy films confirmed the presence of biotin in these films, where an absorbance peak at $1700 \mathrm{~cm}^{-1}$ wavelength represented the carbonyl bond in D-biotin structure, as illustrated in Figure $3 \mathrm{H}$. As expected, this peak was not detectable in the control PPy films. This study confirmed the possibility of incorporation of bioactive molecules in the $\mathrm{CP}$ films electrodeposited through hydrogel stamps. This capability makes the present technique attractive for fabrication of 
patterned films of $\mathrm{CP}$ decorated with biomolecules, or potentially, several different biomolecules in an addressable fashion, for studies of cell adhesion and growth.

In summary, we present a new approach to generate patterned CP films via electropolymerization through hydrogels. Unlike the common electro-deposition where an electrode is submerged in the solution of monomer and dopants, this approach relies on a topographically-patterned hydrogel to deliver the monomer/dopant solutions to selected areas of an electrode surface. We showed that this simple and solution-free electropolymerization technique could produce high-fidelity patterns of CPs with various geometrical shapes. In addition, a hydrogel stamp loaded with polymer precursors can deliver this material to multiple ( $\geq 10$ ) substrates, one after another without re-loading, for rapid and efficient fabrication of a large number of patterned CP films. Furthermore, we demonstrated that by loading the hydrogel stamps with bioactive molecules, in addition to the polymer precursors, this technique produces patterned CP films with entrapped bioactive molecules, which are appealing platforms for cell studies. The most exciting aspect of this approach is that a single hydrogel stamp can be applied to deliver multiple dopants in parallel and thus, to generate patterned $\mathrm{CP}$ films with multiple surface chemistries in a rapid single-step process. We, therefore, expect this simple and readily-accessible method to be applicable in a number of fields including cell and tissue engineering, biomaterials, biosensing, and bioelectronics.

\section{Experimental Section}

\section{Materials}

Agarose powder was obtained from OmniPur (Merck, Darmstadt, Germany). Py, NaPSS, $\mathrm{NaDBS} \mathrm{LiClO}_{4}$, and D-biotin were purchased from Sigma-Aldrich CO. LLC (St. Louis, MO). Bovine serum albumin (BSA) was from Amresco LLC (Solon, OH), and Texas Redconjugated streptavidin was from Molecular Probes (Eugene, OR).

\section{Substrate Preparation}

Plastic coverslips coated with gold, used as conductive substrates, were prepared by an evaporation method using Semicore E-gun/Thermal Evaporator at Penn State Nanofabrication Laboratory. In brief, plastic coverslips $\left(22 \mathrm{~mm}^{2}\right.$, VWR International, Radnor, PA) pre-cleaned with isopropanol and distilled water, were coated with an $8 \mathrm{~nm}$ thick titanium layer as an adhesive layer followed by a $30 \mathrm{~nm}$ thick gold ( $\mathrm{Au}$ ) layer.

\section{Fabrication and Inking of Stamp}

Agarose stamps were prepared by casting the gel on PDMS molds with desired negative features as previously described. ${ }^{[46,47]}$ The agarose content in the hydrogel was varied from 2 to $4 \%(\mathrm{w} / \mathrm{v})$; we applied higher agarose content for the stamps with smaller features ( $\leq 100$ $\mu \mathrm{m})$ to enhance the mechanical robustness of the posts.

For most experiments, the hydrogel stamp was inked by immersion in a solution of monomer/dopant (with concentrations specified in the text) for $\sim 20 \mathrm{~min}$, and the excess fluid on the gel surface was air-dried for $\sim 20 \mathrm{~min}$ at room temperature prior to electrodeposition. 
For selective inking of hydrogel posts, the stamp was first inked with Py by immersing the entire stamp in a Py solution. After air-drying the inked hydrogel, a small volume $(\sim 1 \mu \mathrm{l})$ of the dopant solution was delivered to the individual posts (typically $1 \mathrm{~mm}$ diameter) on the stamp using a micropipette. This process was repeated at least three times with $\sim 5 \mathrm{~min}$ intervals, in order to ensure the delivery of sufficient dopant solutions to each post. The electrodeposition was performed shortly ( $\sim 5 \mathrm{~min})$ after the last inking step. The precise inking of individual posts and short time intervals between inking steps and the electropolymerzation procedure minimized the possibility of diffusing dopants from the inked posts to their neighboring uninked posts.

\section{Electrodeposition}

Electrodeposition was performed by an Autolab electrochemical workstation (Metrohm Autolab B.V., Utrecht, Netherlands). The working electrode was connected to the gold substrate, and the inked stamp was placed onto the substrate (with posts facing down) using a rolling motion to avoid entrapment of air bubbles. Then, the reference and counter electrodes were brought into contact with the hydrogel top surface. The electrodeposition protocol was set by a software Nova 1.8 (Metrohm Autolab B.V.) to apply a constant current, which was calculated based on the current density of $0.5 \mathrm{~mA} / \mathrm{cm}^{2}$ and the surface area in contact with the gold substrate. The electrodeposition time was varied for different post diameters from 1 to $10 \mathrm{~min}$; we typically applied longer deposition time for the stamps with larger features (e.g. $\geq 2 \mathrm{~min}$ for $\geq 700 \mu \mathrm{m}$ features). After the polymerization, the hydrogel was carefully removed from the gold substrate leaving the patterned CP behind. It should be noted that in the presence of high monomer/dopant concentrations ( $\searrow 0.5 \mathrm{M}$ ) in the stamp, longer deposition times ( $>5 \mathrm{~min}$ ) or high current densities $\left(>1 \mathrm{~mA} / \mathrm{cm}^{2}\right.$ ) occasionally led to the difficulty in removal of the stamp from the electrode surface, presumably due to the growth of PPy into the gel network.

\section{Entrapment of Biotin in CP film}

For detection of D-biotin in PPy network by streptavidin binding, we first blocked the exposed substrate with $0.1 \% \mathrm{BSA}$ for $30 \mathrm{~min}$ at room temperature and then incubated the substrate in a solution of $0.1 \mathrm{mg} / \mathrm{mL}$ of Texas Red-streptavidin for 1 hour in dark. After washing the excess streptavidin from the substrate, the level of bound streptavidin to PPy films, with and without biotin, was evaluated under an inverted epi-fluorescence microscopy (Zeiss Axio Observer Z1, Carl Zeiss Microscopy, Oberkochen, Germany).

\section{CP Film Characterization}

Upon electrodeposition, the patterned CP films were imaged under optical microscope (Zeiss Imager Z1, Carl Zeiss Microscopy) at various magnifications. FESEM imaging of these films was performed using Nova NanoSEM 630 from FEI (Hilsboro, OR) at Penn State Material Characterization Laboratory. The thickness measurements were obtained from the Nova NanoSEM software, xT Microscope Control.

Impedance measurements on the substrates were carried out using a three-electrode electrochemical set up from the Autolab potentiostat as previously described. ${ }^{[27]}$ Briefly, the $\mathrm{Ag} / \mathrm{AgCl}$ reference electrode was immersed into a $1 \times \mathrm{PBS}$ (phosphate buffer saline) 
solution, while the working electrode was connected to the substrate and the counter electrode was connected to the electrolyte solution-containing cell. Impedance of the substrates with patterned PPy was measured at a physiologically relevant frequency of 1 $\mathrm{KHz}$ and compared to the bare substrate with no PPy film.

ATR-FTIR spectroscopy of the deposited PPy films was performed using Bruker Vertex 70 (Bruker Corporation, Billerica, MA) at Penn State Material Characterization Laboratory. The samples were scanned 100 times in the wavenumber range of 4000 to $400 \mathrm{~cm}^{-1}$. The spectrum was plotted using the software for Bruker's infrared instruments, Opus version 7.0.

EDS measurements were carried out using an FESEM with a silicon drift detector (area 80 $\mathrm{mm}^{2}$, Oxford Instruments, UK) and the data was analyzed using Aztec Software.

\section{Supplementary Material}

Refer to Web version on PubMed Central for supplementary material.

\section{Acknowledgments}

This work was supported by the College of Engineering and Materials Research Institute at the Pennsylvania State University, a New Investigator Research Grant from the Charles E. Kaufman Foundation at The Pittsburg Foundation (S.M.), and a Penn State University Distinguished Graduate Fellowship (S.P.). Authors would like to thank Erin Richards for her help with the initial experiments.

\section{References}

1. Gustafsson G, Cao Y, Treacy GM, Klavetter F, Colaneri N, Heeger AJ. Nature. 1992; 357:477.

2. Ates M. Mater Sci Eng C. 2013; 33:1853.

3. Rahman MA, Kumar P, Park DS, Shim YB. Sensors. 2008; 8:118. [PubMed: 27879698]

4. Pan LJ, Qiu H, Dou CM, Li Y, Pu L, Xu JB, Shi Y. Int J Mol Sci. 2010; 11:2636. [PubMed: 20717527]

5. Yin Z, Zheng Q. Adv Energy Mater. 2012; 2:179.

6. Heeger AJ. Angew Chem Int Ed. 2001; 40:2591.

7. Shirakawa H, Louis EJ, Macdiarmid AG, Chiang CK, Heeger AJ. Chem Commun. 1977:578.

8. Groenendaal BL, Jonas F, Freitag D, Pielartzik H, Reynolds JR. Adv Mater. 2000; 12:481.

9. Smela E. Adv Mater. 2003; 15:481.

10. Xu LB, Chen W, Mulchandani A, Yan YS. Angew Chem Int Ed. 2005; 44:6009.

11. Cosnier S. Biosens Bioelectron. 1999; 14:443. [PubMed: 10451912]

12. Green RA, Lovell NH, Poole-Warren LA. Acta Biomater. 2010; 6:63. [PubMed: 19563922]

13. Grosjean L, Cherif B, Mercey E, Roget A, Levy Y, Marche PN, Villiers MB, Livache T. Anal Biochem. 2005; 347:193. [PubMed: 16266681]

14. Stauffer WR, Cui XT. Biomaterials. 2006; 27:2405. [PubMed: 16343612]

15. Bax DV, Tipa RS, Kondyurin A, Higgins MJ, Tsoutas K, Gelmi A, Wallace GG, McKenzie DR, Weiss AS, Bilek MMM. Acta Biomater. 2012; 8:2538. [PubMed: 22426287]

16. Gilmore KJ, Kita M, Han Y, Gelmi A, Higgins MJ, Moulton SE, Clark GM, Kapsa R, Wallace GG. Biomaterials. 2009; 30:5292. [PubMed: 19643473]

17. Weng B, Liu X, Shepherd R, Wallace GG. Synth Met. 2012; 162:1375.

18. Green RA, Lovell NH, Poole-Warren LA. Biomaterials. 2009; 30:3637. [PubMed: 19375160]

19. Abidian MR, Daneshvar ED, Egeland BM, Kipke DR, Cederna PS, Urbanchek MG. Adv Healthcare Mater. 2012; 1:762. 
20. Lee JY, Bashur CA, Goldstein AS, Schmidt CE. Biomaterials. 2009; 30:4325. [PubMed: 19501901]

21. Schmidt CE, Shastri VR, Vacanti JP, Langer R. Proc Natl Acad Sci USA. 1997; 94:8948. [PubMed: 9256415]

22. Abidian MR, Martin DC. Biomaterials. 2008; 29:1273. [PubMed: 18093644]

23. Cui XY, Martin DC. Sens Actuators B. 2003; 89:92.

24. Mercey E, Sadir R, Maillart E, Roget A, Baleux F, Lortat-Jacob H, Livache T. Anal Chem. 2008; 80:3476. [PubMed: 18348577]

25. Peng H, Zhang LJ, Soeller C, Travas-Sejdic J. Biomaterials. 2009; 30:2132. [PubMed: 19147223]

26. Wei F, Liao W, Xu Z, Yang Y, Wong DT, Ho CM. Small. 2009; 5:1784. [PubMed: 19384878]

27. Abidian MR, Corey JM, Kipke DR, Martin DC. Small. 2010; 6:421. [PubMed: 20077424]

28. George PM, Lyckman AW, LaVan DA, Hegde A, Leung Y, Avasare R, Testa C, Alexander PM, Langer R, Sur M. Biomaterials. 2005; 26:3511. [PubMed: 15621241]

29. Khodagholy D, Doublet T, Gurfinkel M, Quilichini P, Ismailova E, Leleux P, Herve T, Sanaur S, Bernard C, Malliaras GG. Adv Mater. 2011; 23:H268. [PubMed: 21826747]

30. Ferrell N, Yang YY, Hansford DJ. Microsyst Technol. 2010; 16:1951.

31. Hansen TS, West K, Hassager O, Larsen NB. Adv Mater. 2007; 19:3261.

32. DeFranco JA, Schmidt BS, Lipson M, Malliaras GG. Org Electron. 2006; 7:22.

33. Descamps E, Leichle T, Corso B, Laurent S, Mailley P, Nicu L, Livache T, Bergaud C. Adv Mater. 2007; 19:1816.

34. Donthu S, Pan ZX, Myers B, Shekhawat G, Wu NG, Dravid V. Nano Lett. 2005; 5:1710. [PubMed: 16159210]

35. Gomez N, Lee JY, Nickels JD, Schmidt CE. Adv Funct Mater. 2007; 17:1645. [PubMed: 19655035]

36. Gorman CB, Biebuyck HA, Whitesides GM. Chem Mater. 1995; 7:526.

37. Jang SY, Marquez M, Sotzing GA. J Am Chem Soc. 2004; 126:9476. [PubMed: 15291516]

38. Lim JH, Mirkin CA. Adv Mater. 2002; 14:1474.

39. Schanze KS, Bergstedt TS, Hauser BT, Cavalaheiro CSP. Langmuir. 2000; 16:795.

40. Strong V, Wang Y, Patatanyan A, Whitten PG, Spinks GM, Wallace GG, Kaner RB. Nano Lett. 2011; 11:3128. [PubMed: 21728294]

41. Zhou F, Chen M, Liu WM, Liu JX, Liu ZL, Mu ZG. Adv Mater. 2003; 15:1367.

42. Huang ZY, Wang PC, MacDiarmid AG, Xia YN, Whitesides G. Langmuir. 1997; 13:6480.

43. Beh WS, Kim IT, Qin D, Xia YN, Whitesides GM. Adv Mater. 1999; 11:1038.

44. Xia YN, Whitesides GM. Annu Rev Mater Sci. 1998; 28:153.

45. Kang YJ, Wostein HS, Majd S. Adv Mater. 2013; 25:6834. [PubMed: 24133042]

46. Majd S, Mayer M. Angew Chem Int Ed. 2005; 44:6697.

47. Majd S, Mayer M. J Am Chem Soc. 2008; 130:16060. [PubMed: 18975898]

48. Mayer M, Yang J, Gitlin I, Gracias DH, Whitesides GM. Proteomics. 2004; 4:2366. [PubMed: 15274132]

49. Weibel DB, Lee A, Mayer M, Brady SF, Bruzewicz D, Yang J, DiLuzio WR, Clardy J, Whitesides GM. Langmuir. 2005; 21:6436. [PubMed: 15982051]

50. Stevens MM, Mayer M, Anderson DG, Weibel DB, Whitesides GM, Langer R. Biomaterials. 2005; 26:7636. [PubMed: 15979701]

51. Campbell CJ, Smoukov SK, Bishop KJM, Baker E, Grzybowski BA. Adv Mater. 2006; 18:2004.

52. Lind JU, Acikgoz C, Daugaard AE, Andresen TL, Hvilsted S, Textor M, Larsen NB. Langmuir. 2012; 28:6502. [PubMed: 22443803]

53. Abidian MR, Martin DC. Adv Funct Mater. 2009; 19:573.

54. Wallace GG, Teasdale PR, Spinks GM, Kane-Maguire LAP. Conductive Electroactive Polymers: Intelligent Polymer Systems, Third Edition, Taylor \& Francis. 2008

55. Han MG, Foulger SH. Adv Mater. 2004; 16:231.

56. George PM, LaVan DA, Burdick JA, Chen CY, Liang E, Langer R. Adv Mater. 2006; 18:577. 
A PRECURSORS LOADED HYDROGEL

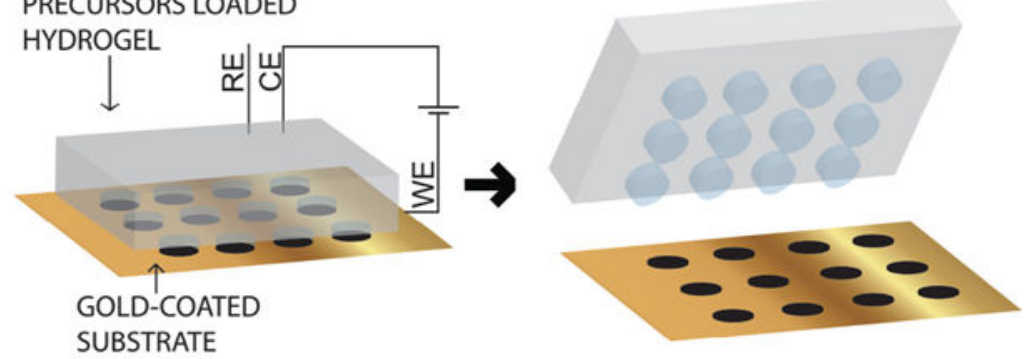

B

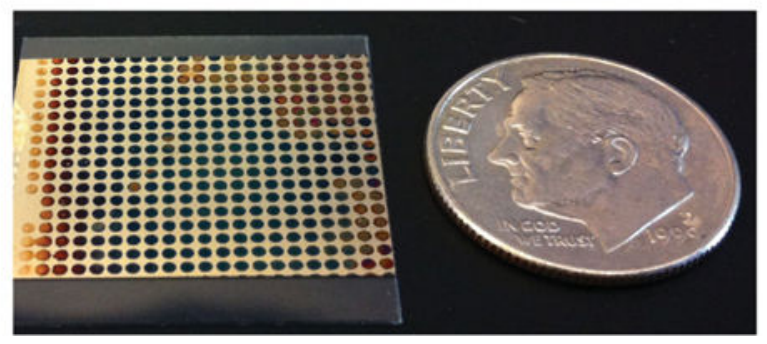

Figure 1.

The concept of hydrogel-mediated electrodeposition of conducting polymer films. (A) Schematic illustration of patterning of conducting polymer films on gold-coated substrates using an agarose stamp that is loaded with the polymer precursor solution. (B) Optical image of a representative patterned PPy film produced by this technique. 
A

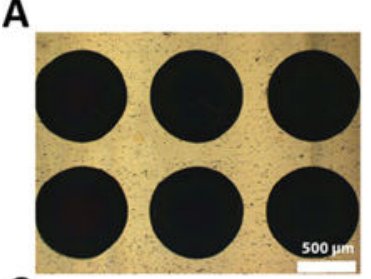

B

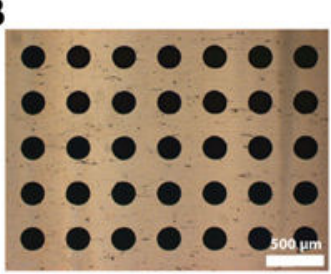

C

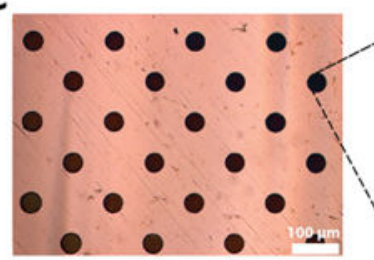

$\mathbf{E}$

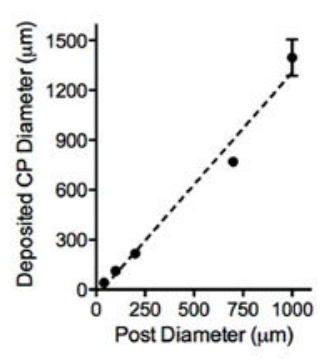

$\mathbf{F}$

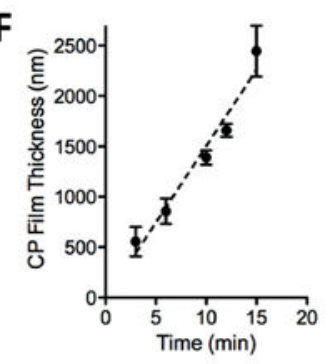

D
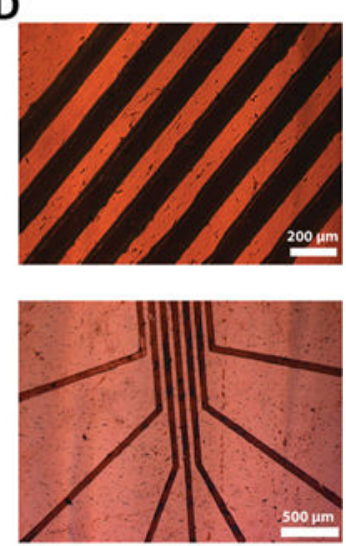

G

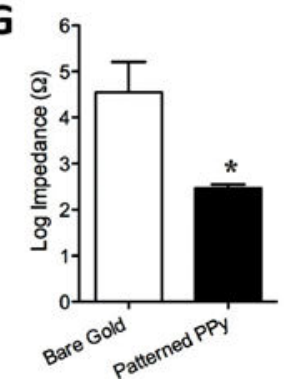

Figure 2.

Characterization of patterned PPy films generated by hydrogel-mediated electrodeposition.

The top panel shows optical images of the PPy films deposited either from a stamp with circular posts of (A) $700 \mu \mathrm{m}$, (B) $200 \mu \mathrm{m}$, and (C) $40 \mu \mathrm{m}$ diameters (and a magnified PPy spot), or from a stamp with (D) linear posts of $100 \mu \mathrm{m}$ width with two different configurations. (E) The change in the size of deposited PPy film spots as a function of the hydrogel post diameter (circular features). Error bars represent standard error of the mean ( $\mathrm{N}$ $260)$, and the dashed line represents the best linear fit to the data $\left(R^{2}=0.9797\right)$. (F) The thickness of the deposited PPy film as a function of the electrodeposition time. Error bars in this graph represent standard error of the mean, and the dashed line shows the best linear fit to the data $\left(\mathrm{R}^{2}=0.9668\right)$. ( $\left.\mathrm{G}\right)$ Comparison of the impedance (log values) of the bare electrode and PPy patterned electrode. The error bars show standard error of the mean $(\mathrm{P}<$ $0.05, \mathrm{~N}=3$ ). 
A

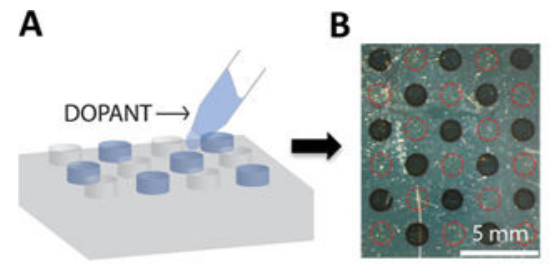

D

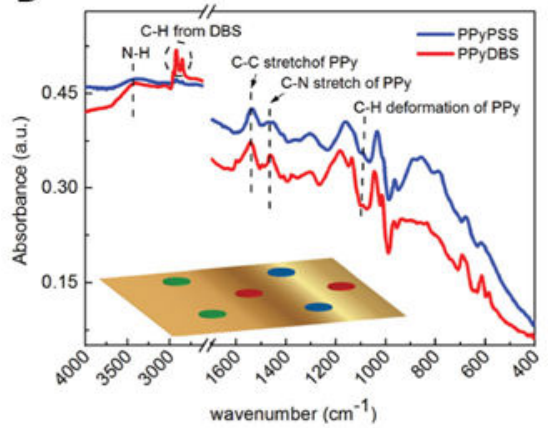

$\mathbf{F}$

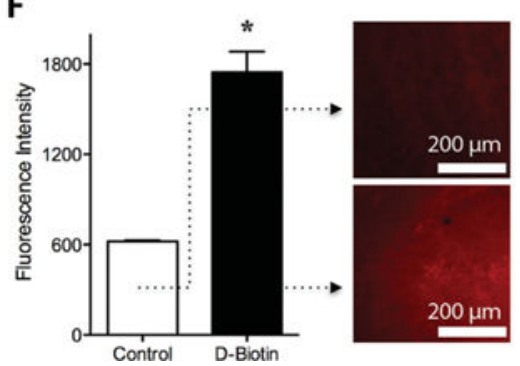

\section{C}

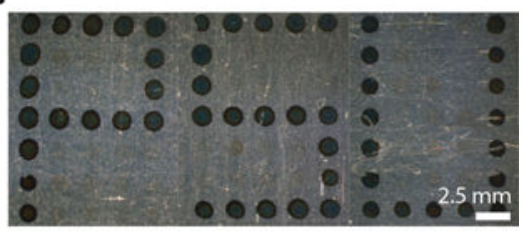

E

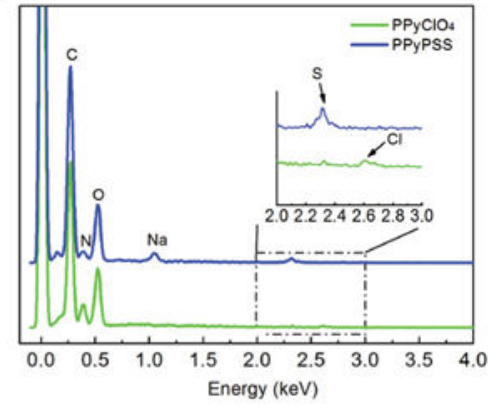

G

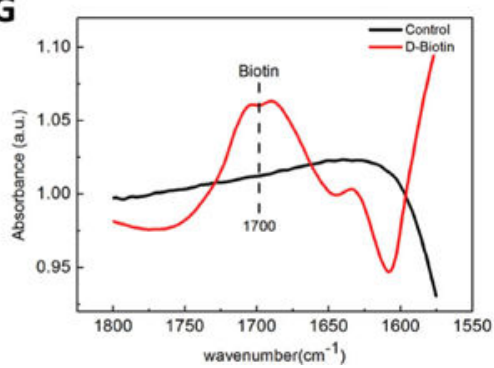

Figure 3.

Hydrogel-mediated electrodeposition of PPy films with multiple chemistries and entrapped biomolecules. (A) Cartoon illustration of selective inking of posts on a hydrogel stamp. The optical images on the right show (B) a PPy pattern produced by a stamp on which the posts were alternatively inked with PSS (dashed red circles show the footprint of posts that carried no dopant) and (C) a patterned PPy with Penn State logo design. (D) ATR-FTIR spectroscopy of PPy spots doped with PSS and DBS on the same substrate, as illustrated in the cartoon inset in this panel where different spots of the patterned PPy were doped with: PSS (blue), DBS (red), or ClO 4 (green). (E) EDS of PPy film spots doped with PSS and $\mathrm{ClO} 4$, on the same substrate examined in panel (D). (F) The fluorescence intensity of PPy films with and without biotin (due to binding of labeled-streptavidin) along with their corresponding fluorescence images. The error bars in the bar graph represent standard error of the mean ( $P<0.05, N=8)$. (G) ATR-FTIR spectroscopy of PPy film with and without entrapped biotin. 